\title{
Management of an Online Game Development Project
}

\author{
Jong H. WI \\ Chung-Ang University \\ E-mail: jhwi@cau.ac.kr
}

\begin{abstract}
This paper discusses a case study of the project management of online content, namely, an online game. For the analysis, the paper presents the patterns of management approach adopted by analyzing a successful case of the development of an online game called "FreeStyle," created by JC Entertainment (JCE). The analysis results reveal that two variables, namely, the CEO's indirect management of the development team and the strong intrinsic teamwork among the development team members, influenced the developers' performance. Finally, the paper illustrates four patterns based on the two aforementioned variables. The pattern of the development project moved from "direct management-low intrinsic teamwork" to "indirect management-high intrinsic teamwork." Due to the pattern change, JCE achieved a high development performance.
\end{abstract}

Keywords: online games, project management, indirect management, intrinsic teamwork

\section{Introduction}

This paper is an exploratory research, which focuses on the organizational management required to develop online content, especially online games, which have different product attributes from manufacturing products.

Korea became the most advanced country in the online game industry in the late 1990s. Korean online games have been exported not only to Asian countries such as China and Vietnam but also to advanced countries such as the U.S., Japan, and those in Europe. In contrast, Western and Japanese game companies have failed to penetrate the global online game market. The fact that the Western and Japanese online game companies are struggling to expand in the global game market is a completely new phenomenon, which was never witnessed in the personal computer (PC) and console game market before (Roh \& Wi, 2007; Wi, in press). 
The characteristics of the Korean online game industry are completely different from those of other traditional industries such as steel, shipbuilding, and automobiles. With regard to the traditional industries, which have developed since the 1960s amidst economic boom, products and services were first developed in advanced countries and then exported to Korea. Korean companies thus gained a competitive advantage through the cost leadership strategy based on the low cost achieved by ready-made technologies and dominant design products (Wi, 2008, in press).

However, the Korean online game industry shows a heterogeneous industrial trajectory, which differs from that of other Korean manufacturing industries. As the Korean game companies succeeded to industrialize the online game market, product development and sector technologies could be established for the first time in the world. Although the technology and product prototype of the online games were derived from "Ultima Online," which was developed by a U.S. game company, Electronic Arts, the complete industrialization of online games can be attributed to Korean companies. Therefore, in the online game industry, Korea is not a follower, but an innovator; moreover, it retains the competitiveness in technology and product quality, and not only in cost. This advantage enabled the Korean game companies to achieve competence and dominance in the global game market. These companies possess the capability of product development, which indicates that they have the capacity to develop games by maintaining a standard quality and are able to meet the global consumers' requirements.

A lot of prior research on successful product development in manufacturing industries already exists. A good example is Clark and Fujimoto (1991), which examines product development in the automobile industry. By conducting a field survey on global automobile manufacturers, they point out that the competence of the Japanese automobile industry is derived from the heavyweight project manager system. They argue that the Japanese companies were able to develop products efficiently because the heavyweight project managers received the enormous privilege of having control over developers from different units of the company. In addition, Nobeoka (1996) elaborates this research to elucidate how efficiently to control multidevelopment projects besides managing single projects.

The above research contributed to broadening the strategy of the product development field. Moreover, this research focused on not only the industry-based macroanalysis but also the product-based microanalysis. In particular, it tried to find out the most suitable development system for efficient product development. In addition, Baldwin and Clark (2000), Henderson and Clark (1990), and Clark (1985) illustrate the new theoretical concept of product architecture. Sanchez and Mahoney (1996) and Wi (2006a, 2008) analyze the architectural change-from integral product to module product or vice versa - and suggest that development systems 
have to be modified in correspondence with the change in product architecture.

However, in contrast to the extensive research carried out on the product development in the manufacturing industry, there is little similar research on the content industry, especially the online content industry. Japanese researchers such as Shintaku, Tanaka, and Yanagawa (2003) analyze the performance of Japanese console software development. They conclude that the pattern of utilizing developers should be based on the game genre. However, their research contains the limitation that it does not analyze the success factors in content development.

Therefore, this paper studies the success factors in the management of product development organizations, by focusing on an online game that was commercially successful.

\section{Research subject: FreeStyle}

The subject of the research in this paper is FreeStyle, an online game developed by JC Entertainment (JCE). JCE was established in 1994. It has developed many popular Korean online games such as War Bible, Redmoon, Joy City, and FreeStyle (refer to Table 1). At present, JCE is servicing FreeStyle in Taiwan, China, the U.S., the Philippines, and Japan. FreeStyle achieved a huge success in both the Korean and Chinese online game markets.

FreeStyle acquired 20 million subscribers and 0.3 million and 80 thousand concurrent users in China
Table 1. History of JCE's game development

\begin{tabular}{|c|c|c|}
\hline Year & Month & Events \\
\hline 2007 & 3 & $\begin{array}{l}\text { Launched the beta service for } \\
\text { "Aeronauts" }\end{array}$ \\
\hline 2005 & 9 & $\begin{array}{l}\text { Entered into FreeStyle license } \\
\text { agreement with } \mathrm{T} 2 \mathrm{CN} \text { in China }\end{array}$ \\
\hline \multirow[t]{2}{*}{2004} & 7 & $\begin{array}{l}\text { Established JCE-China in Shanghai } \\
\text { Digital Park }\end{array}$ \\
\hline & 12 & $\begin{array}{l}\text { Completed one year of service of } \\
\text { FreeStyle in Korea }\end{array}$ \\
\hline \multirow[t]{2}{*}{2003} & 1 & Launched the beta service for "Priest" \\
\hline & 7 & $\begin{array}{l}\text { Launched the casual shooting game } \\
\text { "Rocket Roll" }\end{array}$ \\
\hline 2001 & 9 & $\begin{array}{l}\text { Launched commercial service for } \\
\text { "Joy City" }\end{array}$ \\
\hline \multirow[t]{2}{*}{1999} & 11 & $\begin{array}{l}\text { Established the "WorldnetGames, } \\
\text { Inc." in the U.S., the U.S. subsidiary } \\
\text { of JC Entertainment }\end{array}$ \\
\hline & 12 & $\begin{array}{l}\text { Launched the commercial service for } \\
\text { "Redmoon" }\end{array}$ \\
\hline 1998 & 11 & $\begin{array}{l}\text { Launched the commercial service for } \\
\text { "War Bible" }\end{array}$ \\
\hline 1994 & 5 & Established "Chung Media" \\
\hline
\end{tabular}

and Korea, respectively (Refer to Figure 1). ${ }^{1}$

In 1991, the creator of FreeStyle initiated the development of the game with the proposal of a one-page game development plan. However, this proposal was rejected owing to technological barriers. Instead, JCE decided to develop another casual game called Rocket Roll.

\footnotetext{
${ }^{1}$ In the case of online games, the success or failure of a game depends on the volume of users. As an online game is a type of cyber community, the probability of success directly depends on the total numbers of users.
} 
Figure 1. Tendency of concurrent users and subscribers of FreeStyle

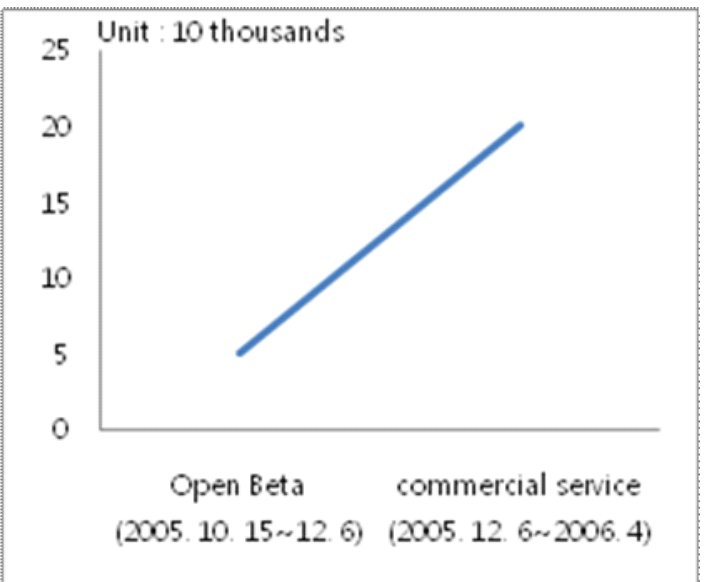

Concurrent users

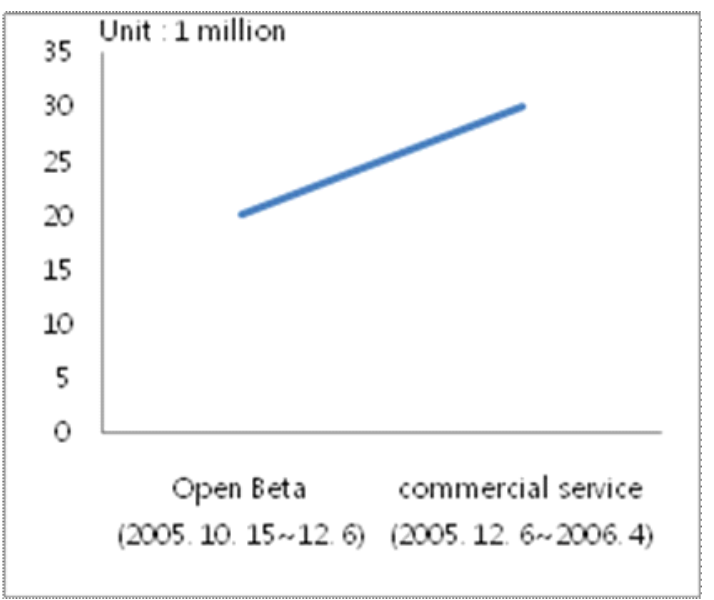

Subscribers

At that time, my colleagues and I thought that we couldn't develop FreeStyle. Therefore, we selected Rocket Roll instead. We thought that we could take up the challenge of developing FreeStyle once again after we finished developing Rocket Roll. I was sure that FreeStyle would be a big opportunity for us as nobody had tried to develop that kind of game before. But the only problem was the lack of capability of my company (CEO).

Before developing Rocket Roll, JCE did not possess the necessary engineering capabilities. It did not even have 3D client programmers. Game engineers who wish to develop sports games have to ensure technical requirements such as the synchronization of motion and animation, high quality rendering, and the stability and synchronization of the server and network. At that time, JCE's engineering capability could not ensure these requirements, and the development of FreeStyle had to be postponed.

Later, a new development team, called Tech Tree (TT) undertook the task of developing Rocket Roll for one year. Although the team successfully developed Rocket Roll, the game failed to acquire a substantial number of users to sustain the game service. Consequently, JCE discontinued the service for Rocket Roll. However, this failure enabled the TT team to acquire valuable assets. Thus, the development process of Rocket Roll led to effective teamwork among the members.

Discussions on the development of the next game began after the commercial failure of Rocket Roll. FreeStyle was once again considered as one of the alternatives after a period of one year and three months since it was first proposed. Although the team continued to encounter technical problems, which hindered the development process, the TT team remained enthusiastic.

\section{2-1. Game concept}

FreeStyle is a street basketball game. The formal version of a basketball game generally consists of ten 
players - five in each team. However, in the case of street basketball, generally, each team consists of three players. The initial proposal for developing FreeStyle explained why JCE decided to develop a basketball game, as follows.

First, players can play basketball in a very small space. Therefore, various playing combinations such as one-to-one or two-to-two or using the whole court or half the court, is possible. Even a one-to-one game is normal. However, a one-to-one game in soccer, baseball, or volleyball would be unusual.

Second, in basketball, each team consists of less than five players - the least number of players among all ball games. This means that one player has to assume various roles and activities in the game. Hence, it can be said that basketball is the most effective sport in terms of fitness, considering the concept of Basket Man, ${ }^{2}$ that is, one character per user in the game (In case of soccer, several players may not even have the opportunity to come in contact with the ball when they play in a 11-player team).

Third, basketball involves quick movements; hence, the players have the opportunity of scoring many points in the game. In other words, the players can easily gain rewards in the game. ${ }^{3}$

FreeStyle is a hip-hoop style street basketball game. "Hip-hoop" is a combined word. "Hip" refers to hip-hop, and "hoop" refers to the basketball hoop. Hip-hoop basketball is played with hip-hop music as a form of a "show-off" street sport,

\footnotetext{
${ }^{2}$ Initial name assigned for the FreeStyle game

${ }^{3}$ JCE's internal documents
}

mainly played by African-American youngsters in the U.S. The players sometimes neglect the rules of the game and are engrossed in demonstrating their skills.

The initial game concept was a five-to-five formal basketball game called Basket Man (BaM). However, this form of basketball contained several problems such as the difficulty of controlling the game and the disruption of the game due to the violation of the complicated basketball rules. The hip-hoop style street basketball was developed as an alternative to the formal basketball. Since there are no formal rules in hip-hoop style basketball, it was not required to consider constraints such as disruptions by players who are not aware of the rules or by unruly players. Furthermore, street basketball allows the use of unique game graphic styles that improve character motions such as kicking the ball or double dribble and make them exciting.

For these reasons, the TT team changed the game concept from a formal basketball to an informal street basketball. Other details, except for the main concept, remained similar to BaM.

\section{2-2. Organizational review process of the} FreeStyle development plan

Every JCE game development undergoes a four-stage review process: (1) submission of a one-page proposal, (2) review of the proposal details, (3) prototype review, and (4) review of the alpha version. A game being reviewed is passed only if it is unanimously approved by the review 
committee. However, the CEO has the privilege to veto the decision of the review committee. The committee consists of 10 employees including the CEO, vice-president, marketing directors, and directors of development.

The TT team formulated the proposal for the development of FreeStyle and submitted it to the review committee. The proposal passed the first stage, that is, one-page proposal, without any problems, but it faced with strong objections from the marketing director and director of development at the second stage, that is, the review of the proposal details. Technological barriers and lack of users for sports games were the main reasons for the oppositions. At that time, the sales figures of sports games such as FIFA Online and NBA Live were not promising in the Korean game market.

In addition, the failure of Rocket Roll gave the TT team a negative reputation. At that time, many engineers had already left the team, and only four core engineers remained. Hence, it was natural that JCE's developers did not focus on FreeStyle until the launch of the beta test.

However, the TT team did not give up the development process. They continually tried to persuade the review committee members to approve the development plan. After the committee meeting, the team members met with the $\mathrm{CEO}$ and requested her to veto the review committee's decision.

The CEO laid down two preconditions to the TT team at the meeting, because she knew that the stockholders would protest if she accepted the TT team's development plan. The two preconditions were that the team had to seek funds from the government to continue their development, and the committee would review the plan once more within a month. After one month, the TT team succeeded in obtaining the committee's unanimous approval, and they received USD200 thousand from the Institute of Software Promotion Agency, a Korean government agency.

\section{2-3. Changes in the CEO's project management approach}

When the development of FreeStyle resumed, the CEO encountered three problems: technological barriers of the sports game, few user's of sports games, and the decision of whether or not to maintain the TT team. She also felt the tremendous pressure of approving the FreeStyle development plan in spite of it being rejected by the review committee.

When I saw the prototype of FreeStyle, I had a rough idea of the game, although some people had negative comments like "the hoop net does not shake when the ball is put in." The prototype showed the basketball court as located under a highway, and it looked so real. The design of the game characters was also improved. I felt that they resolved the critical technological problems. Frankly, I was worried about whether or not they were doing well. But after seeing the prototype, I felt assured. It's not a matter of good or bad quality of the output. The TT team was in a very serious situation in my company because they failed in developing Rocket Roll. Hence, I was worried more about whether they could 


\section{Management of an online game development project}

continue than whether they could succeed. I wanted everybody to recognize that it's not all over even if they failed just one time (CEO).

However, JCE's policy toward managing the development project as described above was not stipulated from the early stage of the company. Before the failure of Rocket Roll, the CEO directed and controlled all the details of the development projects. For example, JCE developed a casual game called Joy City, aimed toward females. JCE once even tried to develop a new community game, Joy City 2030, which was different from Joy City. This development project was initiated by a top-down control approach by the CEO. Nevertheless, the Joy City 2030 project became stagnant without any progress for several months.

Through the failure of Joy City 2030, the CEO realized that direct control over the development project prevented the developers from performing well. She thought that a successful game development would be impossible without achieving a consensus and having a deep understanding of the developers' game development plan. Accordingly, she attempted to change the approach of managing the project team.

I really wanted to develop Redmoon and Joy City 2030, but it didn't go as planned. Motivating developers was not easy. Furthermore, in the case of Redmoon, I could share my ideas with the developers with the help of the comic book with the same name, on which this game was based, but in the case of Joy City 2030, I failed to share my ideas with the developers because there was no original story. They complained that they didn't know what to do and didn't understand what I was saying. This experience helped me realize that I should let the developers develop the game by themselves using their own ideas (CEO).

After the failure of Joy City 2030, the development of the casual game, Rocket Roll, proposed by a development team, commenced in the spring of 2002. At that time, JCE's management approach toward game development changed. The CEO gave the engineers the autonomy in planning and developing a game, while she simply monitored the progress. This approach gave the CEO the advantage of deciding to continue or stop a project based on the progress of the project.

The closed beta service of FreeStyle was launched in the fall of 2004. A closed beta service refers to a test game service for only certain users. The users' responses to this game were tremendous in spite of the developers' concern before the launch of the service. JCE's financial and human support toward FreeStyle increased after the success of the closed beta service. After the closed beta service, an open beta service, which refers to a game service for general users, was launched. The number of concurrent access users increased to 2,000 or 3,000 per day and managed to reach 80,000 in 2006

\section{Managing a project team}

The management of the FreeStyle development project revealed two facts. The first fact pertains to the change in the CEO's management approach toward the development project. Until the failure of 
Joy City 2030, JCE maintained a top-down direct management approach, which means that the CEO had complete control over the projects and monitored the game contents in detail. However, because of the experience where JCE had failed to develop Joy City 2030, the CEO tried to change her management approach toward the game development project. Beginning with the development of Rocket Roll, JCE introduced an "observe and monitor" management approach that involved indirectly monitoring the progress of the game development process.

As compared to the manufacturing industry, the developers' creativity is more important in the content industry, including the online game industry. Direct control over or management of developers sometimes prevents them from expressing their creativity. However, maintaining no control or a laissez-faire management approach results in inefficiency and an increase in the development cost. Therefore, the FreeStyle case raises questions such as "how to manage the contents of a development project?" and "what is the most suitable approach for controlling a project?" The case analysis reveals that indirect control, which does not imply no control, would be more suitable than direct control in managing the development project of an online game. The second finding concerns the high integrity within a development team. Game developers often exhibit Otaku or an obsessive personality. This means that they stick to their arguments and even resort to leaving the team if managers do not accept their
Figure 2. Pattern change of the CEO's management approach and integrity of a team

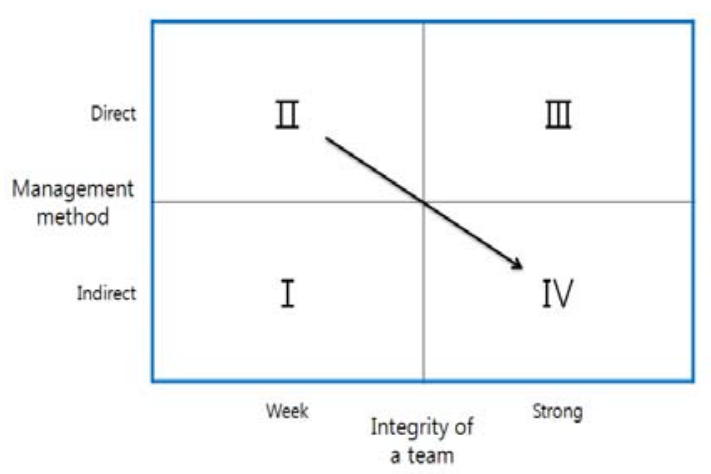

suggestions. Though research on the automobile industry by Clark and Fujimoto (1991) and Nobeoka (1996) insist that while the management of development projects conducted by heavyweight project managers showed good performances, the same cannot be said of online game development. The case analysis of FreeStyle argues that providing the developer with autonomy and resorting to indirect control by the management are essential.

In the case of the manufacturing industry, the products' functional performance is important. Therefore, how to design the layout of each physical function becomes essential. For example, with regard to automobiles, the consumers' satisfaction in terms of speed, stability, and comfort would be prioritized (Clark \& Fujimoto, 1991; Fujimoto, 1997).

However, in the case of the content industry, the users' integral emotional contentment, which is catered to by each product attribute, is 


\section{Management of an online game development project}

important. Users would not be satisfied with a game just because of the excellent design of the characters or the background music. In the case of the content industry, understanding and interaction among developers are more important, than in the manufacturing industry. Therefore, the content development industry depends more on group capabilities, than the manufacturing industry does.

If two factors found in the paper are jointly taken into consideration, four patterns can be obtained as illustrated in Figure 2. This figure was designed taking into consideration the management approach, that is, direct or indirect, and the level of integrity within a team, that is, weak or strong. The analysis reveals that the JCE project moves from pattern II to pattern IV; this indicates a movement from "weak internal integration and direct control" to "powerful internal integration and indirect control." JCE obtained a better development performance through this shift (Refer to Figure 2).

\section{Conclusion}

The paper studies the successful product development management pattern by examining the development project of JCE's FreeStyle. The successful development of FreeStyle could be attributed to two factors - the change in the CEO's management approach toward the development project and the high integrity within a development team. The research set up a hypothesis for the content development industry that states that there is a positive relationship between the CEO's indirect management of a project team or the high integrity within a team and the development performance.

The pattern of "indirect management and powerful integrity" highlights the difference of the online game industry from the manufacturing industry. An almost successful product development of automobile industry would be categorized as type 1 as illustrated in Figure 2. The CEO of the automobile industry does not manage the project team indirectly, and the level of integrity of a team is weaker than it is in the game industry. The reasons behind the different patterns in the two industries were a result of the different product attributes in the two industries.

As product architecture is divided into two types, integral and modular (Baldwin \& Clark, 2000; Iansiti \& Clark, 1994; Ulrich, 1995), the products of the automobile industry can be classified as integral products. However, from the perspective of the online game industry, an automobile is considered as a semi-integral product. The development teams are divided according to the components they use such as engines, radiators, and air conditioners. Although each team frequently holds coordination meetings with other teams (Clark \& Fujimoto, 1991), all the development teams do not possess a high integrity as a united organization as in the case of the online game industry. In other words, the degree of integrity in the two industries is different.

This paper provides directions for future research. One of the topics of research is the game 
genre. FreeStyle, discussed in this study, belongs to the casual sports genre. This genre can be developed in the short term, and the product life cycle is comparatively shorter than that of the massively multiplayer online role-playing games (MMORPG). ${ }^{4}$ Therefore, applying the results of this paper to other game genres will be a good research subject.

\section{References}

Baldwin, C. Y., \& Clark, K. B. (2000). Design rules: The power of modularity. Cambridge, MA: MIT Press.

Clark, K. B. (1985). The interaction of design hierarchies and market concepts in technological evolution. Research Policy, 14, 235-251.

Clark, K. B., \& Fujimoto, T. (1991). Product development performance: Strategy, organization and management in the world auto industry. Boston: Harvard Business School Press.

Henderson, $\quad$ R. $\quad$ M., \& Clark, K. B. (1990). Architectural innovation: The reconfiguration of existing product technologies and the failure of established firms. Administrative Science Quarterly, 35, 9-30.

Iansiti, M., \& Clark, K. B. (1994). Integration and dynamic capability: Evident from product development in automobiles and mainframe industry. Industrial and Corporate Change, 3(3),

${ }^{4}$ MMORPG is a game genre wherein more than hundred users (sometimes more than million users) can access the game server and play a specific role for a certain type of character such as human, elf, and dwarf.
$557-605$.

Fujimoto, T. (1997). Seisan shisutemu no shinkaron [Evolution of product system]. Tokyo: Yuhikaku. (In Japanese)

Nobeoka, K. (1996). Multiproject strategy: Post lean product development management. Yuhikaku. (Japanese)

Roh, S., \& Wi, J. H. (2007). The development process and future of Korean online game industry. Seoul, Korea: Seoul National University Press.

Sanchez, R., \& Mahoney, J. T. (1996). Modularity, flexibility, and knowledge management in product and organization design. Strategic Management Journal, 17(Winter Special Issue), 63-76.

Shintaku, J., Tanaka, T., \& Yanagawa, N. (2003). Economic analysis on game industry: Structure and Business Strategy on Game Software Industry. Tokyo: Toyokeizaishinposha. (In Japanese)

Ulrich, K. (1995). The role of product architecture in the manufacturing firm. Research Policy, 24, $419-440$

Wi, J. H. (in press). Innovation and strategy of online games. London: Imperial College Press.

Wi, J. H. (2008). Industrial development strategy of online games. Beijing, China: Tsinghua University Press. (In Chinese)

Wi, J. H. (2008). Innovation strategy of Japanese firms. Seoul, Korea: Jipmundang. (In Korean)

Wi, J. H. (2006a). Organizational behavior of established firms to a disruptive innovation: The case of NEC's behavior in the Japanese 


\section{Management of an online game development project}

laptop computer industry. Asian Journal of Technology Innovation, 14(2), 29-48.

Wi, J. H. (2006b). Business strategy of online games. Seoul, Korea: JeWoo Media. (In Korean)

[Received August 5, 2008; accepted October 13, 2008] 
